\title{
Transformational and Transactional Leadership Styles of Nurse Managers and Job Satisfaction among Filipino Nurses: A Pilot Study
}

\author{
Lucky Fitzgerald R. Lapeña ${ }^{1}$, Cyruz P. Tuppal ${ }^{2}$, Bradley Goldie K. Loo ${ }^{3}$, \\ Kenji Hennessy C. Abe \\ ${ }^{1}$ Graduate School of Nursing, Concordia College, Manila, Philippines \\ ${ }^{2}$ Senior Clinical Tutor, Ministry of Health, Muscat, Sultanate of Oman; Adjunct Professor, St. Paul \\ University Philippines System, Tuguegarao City, Philippines \\ ${ }^{3}$ Professor, Graduate School of Nursing, Concordia College, Manila, Philippines \\ ${ }^{4}$ Clinical Education Coordinator, Prince Sultan Military Medical City, Riyadh, \\ Kingdom of Saudi Arabia \\ Corresponding Author: Cyruz P. Tuppal (drcyruztuppal@gmail.com)
}

\begin{abstract}
Background: Due to the paucity of literature in leadership styles and job satisfaction within the Philippine context, this descriptive correlational study among Filipino nurses (FNs) was piloted in a selected tertiary hospital in Manila.

Purpose: This study utilized a descriptive correlational research design to describe aspects of a situation and explore relationships among leadership styles and job satisfaction, without seeking to establish causal connections

Methods: Before the data collection, the researchers secured an administrative and ethical clearance from the executive assistant to the President thru the Officer-in-Charge of the Nursing Service Division of the hospital. There were 285 staff nurses, of which only 100 nurses were qualified to have at least one year of experience. Three sets of questionnaires were disseminated, and responses were treated analyzed using the descriptive statistics to describe the demographic and work profile, LS, and JS while Pearson R correlation was used to measure the relationship between LS and JS.

Results: Using self-administered questionnaires, FNs rated their level of satisfaction $(M=3.37)$ from high to a moderate extent along with professional autonomy $(M=3.91)$, work environment $(M=3.81)$, work assignment $(M=3.61)$, and benefits $(M=2.71)$. Participants agreed that their nurse managers utilized either transformational or transactional leadership styles. Findings indicate that transformational $(r=0.558$, $p<0.000)$ and transactional $(r=0.528, p<0.000)$ leadership styles of nurse managers were correlated to nurses' job satisfaction.

Conclusion: The finding explicates that FNs were satisfied in their professional autonomy, work environment, and work assignment but moderately satisfied in work benefits which were also apparent in the global literature. Furthermore, the results indicate that leadership styles are related to the overall job satisfaction of among nurses.
\end{abstract}

Keywords: Job satisfaction; leadership styles; nursing service; Philippines 


\section{BACKGROUND}

Job satisfaction (JS) as a concept and a subject of interest has received recognition as the most researched variable in various disciplines (Judge \& Klinger, 2008). As early as the 1970s and to the current date, JS continuously emerges as a measure of individual performance and organization vitality (Burke, 2004; Locke, 1976; Maurits, de Veer, Groenewegen, \& Francke, 2017; Morsiani, Bagnasco, \& Sasso, 2017; Spector, 1997).

JS is an emotional state where an individual appraises the job that facilitates achieving and facilitating of one's job values (Locke, 1976, p. 1304; Spector, 1997). JS is further viewed using a two-pronged lens. First, the humanitarian perspective views fairness and dignity at work that should be observed among employees. Second, the utilitarian perspective inculcates that JS affects the employee's behavioral or attitudinal aspects (Spector, 1997). From the definitions and underpinnings, it can be deduced that JS illuminates the person's overall feelings about the work and the organization as explicitly mentioned in Maslow's Hierarchy of Needs (Maslow, 1943), Herzberg Theory of Motivation (Herzberg, 1966) and Job Satisfaction Theory (Locke, 1976). These three distinct and interrelated theories reflect the antecedents and outcomes of JS.

In the most recent nursing studies, JS embeds several domains like autonomy (AlShamari, Paulose, Ou, \& Ngwakongnwi, 2015; Kuwano, Fukuda, \& Murashima, 2016; Wu et al., 2014), work environment (Goh, Lee, Chan, \& Chan, 2015; Huong Nguyen \& Prachusilpa, 2016; Kubichka, 2016; Naveed, Hussain, Sarfraz, Afghan, \& Waqar, 2016; Wang et al., 2015), workload assignment (Leineweber et al., 2016; Stuart, Jarvis, \& Daniel, 2008; Van Bogaert, Clarke, Willems, \& Mondelaers, 2013), and benefits (Atefi, Lim Abdullah, Wong, \& Mazlom, 2015; Singh \& Loncar, 2010; Wang et al., 2015). JS also influences the service quality (Abdelhafiz, Alloubani, \& Almatari, 2016; Atefi et al., 2015), job performance (Huong Nguyen \& Prachusilpa, 2016), wellbeing or quality of life (Galletta, Portoghese, Coppola, Finco, \& Campagna, 2016; Gurková, Čáp, Žiaková, \& Ďurišková, 2012; Ibrahim et al., 2016), burnout (Jiang, Li, Gu, \& Lu, 2016), and turnover (Alsaraireh, Quinn Griffin, Ziehm, \& Fitzpatrick, 2014; Delobelle et al., 2011; Goh \& Lopez, 2016). Through the identification of JS-related facets, leaders in the organizations can distinguish the individual differences and ways to achieve a high level of employee's JS. Thus, leaders should have the drive to develop an organization that is evolving, adaptive, and responsive to the growing needs of the workforce.

Like any other organizations, hospital as a system comprises of subsystems including nursing that needs a leadership that can address the needs of the nursing workforce. As nursing evolves from a handmaiden to an autonomous discipline, it should be the forefront to address various alternatives, expectations, and experiences of nurses and their level of JS (Burke, 2004). Thus, leadership becomes inherent to nursing and requires a new evolving mechanism to address the issue of JS despite individual differences. Nurse managers share a mutual understanding that the way they lead and manage their respective unit will affect the way nurses perceive their JS. The leadership styles of nurse managers vary. The transactional leaders are those who focus on the mutual exchange of relationship with the follower, while transformational leaders emphasize mutuality towards greater awareness of motivation and morality (Bass, 1985; Burns, 1978). 
The hospital as a multidimensional system is a crucial enabler of JS among nurses. The healthcare delivery comprises of nurses holding various positions. As expected, nurse managers plan, direct, control, and evaluate the overall unit or department and nurses' performance. Nurse managers need to ensure that a healthy environment facilitates the formation of a trusting relationship associated with quality care (Abdelhafiz et al., 2016; De Cremer, 2003; Wong, 2015). Nurse managers who can lead others to do the same magnify a quality of an authentic leader-employee relationship, which in return influences self-esteem and job satisfaction (Ugwa, 2014). In this juncture, leadership styles and job satisfaction should be given much attention by the nursing management not only to sustain the organizational functioning but also to build strategic actions to improve nurses' performance and to establish a balance of the transformational and transactional leadership at all levels.

The Philippines has been coined as the number one exporter of nurses around the globe (Lorenzo, Galvez-Tan, Icamina, \& Javier, 2007; Tuppal, 2017). The call for overseas work prompted many Filipino nurses (FNs) due to the economic prosperity that developed countries can offer. Due to the compatibility of the education, dexterity in skills, and other essential attributes, FNs have the leverage to be highly valued in various hospitals overseas (Lorenzo et al., 2007; Pastor, 2015; Tayao-Juego, 2016; Tuppal, 2017). As FNs continue to migrate for whatever reasons, a shortage in the nursing workforce becomes inevitable. Consequently, those FNs who opt to work in the country to date need to shoulder around 30 or more patients in every shift as opposed to the ideal nurse-patient ratio of 1:12 (The Manila Times, 2016). From the same report, a regular nurse in a government hospital receives a maximum of P18,000 every month despite an aggressive lobbying of the Philippine Nurses Association (PNA) to standardize the salary grade to P25,000 as stipulated in the Republic Act 7305 (Magna Carta of Public Health Workers) and Republic Act 9173 (Nursing Law). Almost 500,000 registered nurses are working in public and private hospitals while 200,000 working in different fields. With the urgent hiring from the Middle East, United Kingdom, Ireland, Germany, Japan, Canada, and the United States, FNs would leave the country in years to come as nursing is a fastest-growing and in-demand occupation (Tayao-Juego, 2016; The Manila Times, 2016; Tuppal, 2017). Undeniably, with the current economic uncertainty and unpredictability in the country, FNs would choose to work overseas (Lorenzo et al., 2007; Tuppal, 2017). As nurses have no other choice but to leave the country, the hospitals would abruptly experience turnover, which requires available staff to fill the void leading to a cyclical process of high stress, burnout, fatigue, and dissatisfaction (Perez, 2014).

Due to the paucity of evidence that explores the relationships between JS and LS among nurse managers in the Philippines, it is then pivotal to give much attention to these domains where the gap exists. It should be noted that many studies have been conducted in the developed countries about nurse's JS and yet limited on its identified significant nexus with the two contemporary leadership styles - transformational and transactional. Through this study, it is hoped to provide a groundwork for understanding such constellation of relationships. 


\section{PURPOSE}

This study utilized a descriptive correlational research design to describe aspects of a situation and explore relationships among leadership styles and job satisfaction, without seeking to establish causal connections (Polit \& Beck, 2016).

\section{METHODS}

Before the data collection, the researchers secured an administrative and ethical clearance from the executive assistant to the President thru officer-in-charge of the Nursing Service Division of the hospital. According to the census of the nursing office, there were 285 staff nurses, of which only 100 nurses were qualified to have at least one year of experience. Those informed, consented, and eligible participants were given each a sealed envelope that contained the packet information, and sets of a selfadministered questionnaire on demographic profile, leadership styles, and job satisfaction. They were asked to return the sealed envelope to the researcher without an identifiable information. The participants were also informed that their participation was voluntary and can withdraw anytime.

Research instruments were composed of three parts. Part I describes the demographic and work profile of the participants. Part II evaluates the eight job-related statements to indicate their level of job satisfaction. It measures the nurses' satisfaction as affected by the four job components identified which are autonomy, work environment, job content, and benefits using a 4-point Likert scale for JS (1=not at all, $2=$ low extent, $3=$ moderate extent, $4=$ high extent). Part III was designed to distinguish between the Transactional ( 8 statements) and Transformational (8 statements) and rated using a 4-point Likert scale (1=not at all, 2=occasionally, 3=sometimes, 4=always). Test-retest reliability was performed to ensure that the sets of the modified questionnaires were reliable for JS $(\alpha=0.937)$ and LS $(\alpha=0.956)$.

After the data entry in the Microsoft Excel and Statistical Package for the Social Sciences (SPSS) (IBM Corp., 2015), data were cleaned and analyzed using normality outliers. The quantitative data were treated using SPSS version 23 specifically descriptive statistics including frequency, percentage, and means to analyze the aggregated data of demographic and work profile, leadership styles, and job satisfaction. The significant relationships between the leadership styles and job satisfaction were treated using Pearson R correlation.

\section{RESULTS}

\section{Demographic and work profile}

Thirty-eight participants belonged to the age group between 25-29 (38\%), female with eighteen (82\%) and single with sixty-eight (68\%). In the length of service, 50 out of 100 respondents had a work experience of 1-2 years (50\%), BSN degree holders with 90 (90\%) and earned monthly ranged from P12000 to P15000 (93\%). Most of the participants surveyed were from the medical ward with 24 (24\%). 
Table 1. Demographic profile of the participants $(n=100)$

\begin{tabular}{|c|c|c|}
\hline Demographic Profiles & Frequency & $\%$ \\
\hline \multicolumn{3}{|l|}{ Age } \\
\hline $20-24$ & 30 & 30 \\
\hline $25-29$ & 38 & 38 \\
\hline 30-34 & 13 & 13 \\
\hline $35-39$ & 8 & 8 \\
\hline $40-44$ & 10 & 10 \\
\hline $45-49$ & 1 & 1 \\
\hline \multicolumn{3}{|l|}{ Gender } \\
\hline Male & 18 & 18 \\
\hline Female & 82 & 82 \\
\hline \multicolumn{3}{|l|}{ Civil Status } \\
\hline Single & 68 & 68 \\
\hline Married & 32 & 32 \\
\hline \multicolumn{3}{|l|}{ Years of Experience in the Workplace } \\
\hline $1-2$ & 50 & 50 \\
\hline $3-4$ & 13 & 13 \\
\hline $5-6$ & 16 & 16 \\
\hline $7-8$ & 7 & 7 \\
\hline $9-10$ & 6 & 6 \\
\hline $11-12$ & 3 & 3 \\
\hline $13-14$ & 2 & 2 \\
\hline $15>$ & 3 & 3 \\
\hline \multicolumn{3}{|l|}{ Highest Education Obtained } \\
\hline BSN & 90 & 90 \\
\hline with units in Masters & 9 & 9 \\
\hline Master's Degree & 1 & 1 \\
\hline \multicolumn{3}{|l|}{ Gross Income } \\
\hline $\mathrm{P} 12,000-\mathrm{P} 13,000$ & 93 & 93 \\
\hline P14,000-P15,000 & 7 & 7 \\
\hline \multicolumn{3}{|l|}{ Area of Assignment } \\
\hline Medical Ward ( $6^{\text {th }}$ floor $)$ & 24 & 24 \\
\hline Surgical Ward $\left(5^{\text {th }}\right.$ floor and $16^{\text {th }}$ floor $)$ & 6 & 6 \\
\hline Pediatric Ward (4-A and 5-A) & 9 & 9 \\
\hline Obstetric Ward (3-A) & 3 & 3 \\
\hline Delivery Room Complex & 12 & 12 \\
\hline Operating Room Department & 15 & 15 \\
\hline Emergency Room Department & 7 & 7 \\
\hline Cardiac Catheter Laboratory & 2 & 2 \\
\hline Medical Intensive Care Unit & 6 & 6 \\
\hline Neonatal Intensive Care Unit & 4 & 4 \\
\hline Behavioral Medicine Unit & 3 & 3 \\
\hline Annex / Charity Ward & 5 & 5 \\
\hline Post Anesthesia Care Unit / Surgical ICU & 4 & 4 \\
\hline
\end{tabular}

\section{Leadership styles of nurse managers}

Table 2 shows that the nurse managers exemplify either transformational $(M=3.44$, always) or transactional (M=3.33, always). It can be inferred that in transactional 
leadership styles, top three attributes of nurse managers include focusing attention on irregularities, mistakes, expectations, and deviations from standards ( $M=3.66$, always), guide nurses in making decisions to establish goals by clarifying roles and task requirements $(M=3.55$, always $)$ and specify the importance of having a strong sense of purpose ( $M=3.47$, always). In terms of the transformational leadership styles, the top three nurse managers' attributes include increasing willingness of nurses to try harder $(\mathrm{M}=3.69$, always) and motivating nurses to do more than what is expected $(\mathrm{M}=3.69$, always), talking about the organization's most important values and beliefs $(M=3.45$, always) and treating nurses as individuals rather than just a member of the group $(\mathrm{M}=3.45$, always $)$.

Table 2. Leadership styles among nurse managers

\begin{tabular}{|c|c|c|}
\hline Leadership Styles & Mean & Interpretation \\
\hline \multicolumn{3}{|l|}{ Transactional } \\
\hline \multicolumn{3}{|l|}{ The nurse manager: } \\
\hline $\begin{array}{l}\text { 1. Guides me in making decisions to establish goals by } \\
\text { clarifying roles and task requirements }\end{array}$ & 3.55 & Always \\
\hline 2. Directs my attention towards failures to meet standards & 3.46 & Always \\
\hline $\begin{array}{l}\text { 3. Focuses attention on irregularities, mistakes, expectations, } \\
\text { and deviations from standards }\end{array}$ & 3.66 & Always \\
\hline $\begin{array}{l}\text { 4. Discusses in specific terms who is responsible for achieving } \\
\text { performance targets }\end{array}$ & 3.31 & Always \\
\hline $\begin{array}{l}\text { 5. Makes clear what one can expect to receive when } \\
\text { performance goals are achieved }\end{array}$ & 3.40 & Always \\
\hline 6. Expresses satisfaction when I meet expectations & 3.36 & Always \\
\hline $\begin{array}{l}\text { 7. Specifies the importance of having a strong sense of } \\
\text { purpose }\end{array}$ & 3.47 & Always \\
\hline 8. Waits for things to go wrong before taking action & 2.44 & Occasionally \\
\hline Overall Mean & 3.33 & Always \\
\hline \multicolumn{3}{|l|}{ Transformational } \\
\hline \multicolumn{3}{|l|}{ The nurse manager: } \\
\hline 9. Increases my willingness to try harder & 3.69 & Always \\
\hline 10. Motivates me to do more than what is expected of me & 3.69 & Always \\
\hline 11. Provides me with assistance in exchange for my effort & 3.16 & Always \\
\hline 12. Seeks differing perspectives when solving problems & 3.35 & Always \\
\hline $\begin{array}{l}\text { 13. Treats me as in individual rather than just a member of the } \\
\text { group }\end{array}$ & 3.45 & Always \\
\hline 14. Articulates a compelling vision of the future & 3.36 & Always \\
\hline $\begin{array}{l}\text { 15. Talks about the organization's most important values and } \\
\text { beliefs }\end{array}$ & 3.45 & Always \\
\hline 16. Talks optimistically about the future & 3.37 & Always \\
\hline Overall Mean & 3.44 & Always \\
\hline
\end{tabular}

Note: 4.00-3.25 Always, 3.24-2.49 Sometimes, 2.48-1.73 Occasionally, 1.72-1.00 Never

\section{Job satisfaction among nurses}

Table 3 shows the job satisfaction of staff nurses with the total mean of 3.37 (high extent). Furthermore, staff nurses were satisfied with their jobs as reflected in the four components of job satisfaction particularly professional autonomy $(\mathrm{M}=3.91$, high 
extent), work environment ( $\mathrm{M}=3.81$, high extent), work assignment $(\mathrm{M}=3.61$, high extent) and benefits ( $\mathrm{M}=2.61$, moderate extent).

Table 3. Job satisfaction of nurses

\begin{tabular}{lcc}
\hline Job Satisfaction Indices & Mean & Interpretation \\
\hline Professional Autonomy & 3.91 & High Extent \\
1.Allows me to make independent nursing care decisions & 3.84 & High Extent \\
2. Allows me to be entirely responsible for those decisions & 3.99 & High Extent \\
Work Environment & 3.81 & High Extent \\
3.Provides adequate resources necessary for patient care & 3.71 & High Extent \\
4.Provides good collaboration between nurses and physicians & 3.92 & High Extent \\
Work Assignment & 3.61 & High Extent \\
5.I receive satisfactory work hour shifts by receiving enough & 3.44 & High Extent \\
$\quad$ time to complete patient care task & & \\
6. My unit provides a variety of clinical challenges and provides & 3.79 & High Extent \\
$\quad$ opportunity to use my nursing skills & & \\
Benefits & 2.16 & Low Extent \\
7.I receive adequate salary & 2.25 & Low Extent \\
8.There are adequate additional financial benefits other than & 2.08 & Low Extent \\
$\quad$ salaries such as healthcare benefits, sick leave, and vacation & & \\
$\quad$ leaves & & \\
Note: 4.00-3.25 High Extent, 3.24-2.49 Moderate Extent, 2.48-1.73 Low Extent, 1.72-1.00
\end{tabular}

Not at all

\section{Relationships between the leadership styles and job satisfaction}

A Pearson product-moment correlation coefficient was used to measure the relationships between the leadership styles of nurse managers and job satisfaction among nurses. There was a positive correlation between the job satisfaction and transactional leadership $(r=0.558, p<0.000)$, transformational leadership $(r=0.526$, $p<0.000)$.

Table 4. Relationship between leadership styles and job satisfaction

\begin{tabular}{llcc}
\hline & & Transactional & Transformational \\
\hline Overall Job & Pearson Correlation & $.558^{* *}$ & $.526^{* *}$ \\
Satisfaction & Sig. (2-tailed) & .000 & .000 \\
& $\mathrm{~N}$ & 100 & 100 \\
\hline
\end{tabular}

** Correlation is significant at the 0.01 level (2-tailed)

\section{DISCUSSION}

\section{Job satisfaction of FNs}

Results indicate that FNs were highly satisfied with their job $(\mathrm{M}=3.37)$ along with the four domains. Professional Autonomy was rated to a great extent as it defines the independence among nurses to act and decide in managing their patients $(\mathrm{M}=3.81)$. AlShamari et al. (2015) found out in a cross-sectional study among nurses $(n=435)$ in Qatar were more satisfied compared to their local counterparts. Autonomy and contract type were statistically significant predictors of JS aside from financial and non-financial benefits. However, Kuwano et al. (2016) surmised that professional autonomy of 
Japanese nurses $(n=238)$ caring for non-Japanese patients was significantly lower than when caring for Japanese patients. Kuwano et al. (2016) suggested that nurses should develop an intercultural sensitivity to provide culturally competent care to increase JS. From among nurses in a regional hospital in Taiwan $(n=196)$, Wu et al. (2014) revealed that professional autonomy was positively associated with JS although cumbersome and busy workload can reduce the capacity of nurses to work efficiently.

Interpersonal relations with colleagues affect nurse's view on JS about the work environment $(\mathrm{M}=3.81)$. A positive work environment cultivates appreciation, interdependence, and cooperation (Bai, 2016). The majority of the participants in this study have at least 1-2 years working experience. Thus, the work environment plays a vital role towards work motivation and job satisfaction among these entry-level nurses (Laschinger, Zhu, \& Read, 2016). Naveed et al. (2016) also found out among nurses $(n=81)$ in a selected children hospital in Pakistan. In China, nurses $(n=444)$ working in 22 venerable institutions were surveyed to examine the job satisfaction and its contributing factors (Wang et al., 2015). The practice environment was associated with nurses' job satisfaction reflected on the nurse-physician collegial nature of relationships. Kubichka (2016) reiterated that negative relationships among colleagues contribute to the stressful conditions that precipitate low job satisfaction among nurses $(n=427)$. Huong Nguyen and Prachusilpa (2016) concluded that work conditions and psychological empowerment positively and significantly related to job satisfaction among professional public health nurses $(n=356)$. In a tertiary public-funded hospital in Singapore, migrant nurses surveyed $(n=495)$ reiterated that a supportive environment is essential to achieve a high level of satisfaction (Goh \& Lopez, 2016). On the contrary, Goh et al. (2015) also indicated that job satisfaction was negatively correlated with the work environment and pre-existing Chinese nurses did not help their colleagues for a more efficient acculturation.

FNs were highly satisfied with their workload assignment $(\mathrm{M}=3.61)$. Despite there are many activities on every shift, nurses would find ways to ease the burden of completing the assigned tasks. Patient activities, nurse-led interventions, documentation, pre- and post-endorsement, and follow-ups are the everyday activities that nurses do. However, due to a stressful environment, nurses' level of job satisfaction may tend to decrease. Such decrease has been associated with insufficient control over the workload including the scheduling pattern. Atefi et al. (2015) surmised that about $76 \%$ Iranian nurses surveyed $(n=421)$ working at a large hospital that they do not have a shared decision regarding scheduling and about $75 \%$ agreed that the workload was unreasonable and erratic. Work assignment of nurses requires consensus among nurse managers and nurses themselves. A study in Pakistan revealed that lack of involvement in a decision that requires nurses' inputs was a significant factor of job satisfaction nurses in a selected children hospital (Naveed et al., 2016). Leineweber et al. (2016) suggested that work schedule flexibility can be utilized to alleviate dissatisfaction and intent to leave from a multi-country and multilevel study conducted among nurses $(n=23,076)$ from 2,020 units in 384 hospitals in 10 European countries.

Work benefits including salary have been linked to job satisfaction. In this study, nurses were moderately satisfied with the benefits that they receive $(M=2.10)$ in contrast to 
Atefi et al. (2015) who found out that Iranian nurses were dissatisfied with their benefits, often felt unappreciated and underpaid. Al-Shamari et al. (2015) in a survey from a tertiary hospital in Qatar among expatriate nurses $(n=435)$ rated their job satisfaction higher compared to local nurses. Results indicate that either financial or non-financial benefits are the predictor of nurses' job satisfaction. Wang et al. (2015) concurred similar findings among Chinese nurses from various hospitals in an old setting.

\section{Leadership styles and job satisfaction}

With the advent of a modernized health care delivery, radical reforms, and change in basic assumptions, nurse managers along with the hospital administrators need to develop a healthy working environment for the workforce. Nurse managers though can embrace the dynamic management processes; they are also mandated to lead others to achieve the institutional vision and mission. Nurse managers should learn how to facilitate to meet the needs and expectations of other nurses under their supervision. Findings in this study indicate that transformational $(r=0.526, p<0.000)$ and transactional $(r=0.558, p<0.000)$ leadership styles of nurse managers are correlated to nurses' JS similar to the study findings of Aarons (2006) among public-sector mental health service clinicians $(n=303)$. Such findings further explain that regardless the type of leadership styles used by the nurse managers, nurses' JS would either be low or high. This means that JS is dependent on how nurses perceive the importance of leadership styles since either transformational and transactional could be beneficial for nurses, nurse managers, and the organization. Several studies reveal that nurses prefer transformational rather than transactional (Perez, 2014). Abualrub and Alghamdi (2012) show a significant moderate correlation in the positive direction between transformational leadership style and nurses' job satisfaction $(r=0.45, p<0.001)$, and significant weak relationship in the negative direction between transactional leadership style and job satisfaction $(r=-0.14, p<0.01)$. Other studies found out that transformational leadership styles are more preferred in many hospitals

The early pioneers made a clear distinction between transformational and transactional leadership styles. Transformational leaders heighten the motivation of their followers towards a shared vision while Transactional leaders focus on the roles including supervision and organization of daily progress within the organization (Burns, 1978; Burns, 2003). From these attributes, nurse managers should find balance with the leadership styles that would be significant in the workflow and the interrelation mechanism of the workforce as presented in (Aarons, 2006; Miller, 2017; Perez, 2014). In support of this assumption, Figure 1 presents the LS-JS Constellation Paradigm that sustains such balance between the leadership styles (i.e., transformational versus transactional) and job satisfaction (autonomy, work environment, work assignment, and benefits).

If nurse managers would be able to build a strong foundation in both leadership styles, as transactional leaders, for instance, nurse managers can direct others to identify specific goals to be achieved daily. For novice nurses, they would further need assistance from the nurse managers to be more acquainted and would feel affirmed and appreciated. As effective transactional leaders, nurse managers understand how to 
reciprocate the outcomes of an excellent service delivery. Nurse managers can provide a reward system that would motivate others to perform effectively and efficiently. About the problems or issues arising in the unit, nurse managers can immediately develop strategic approaches. On the other note, as transformational leaders, nurse managers exemplify a shared vision on a long-term basis that nurtures innovativeness, inspiration, enthusiasm, and trust. If nurse managers can illumine such vision, it would also motivate and heighten the willingness of other staff to exceed the expectations regarding performance and productivity.

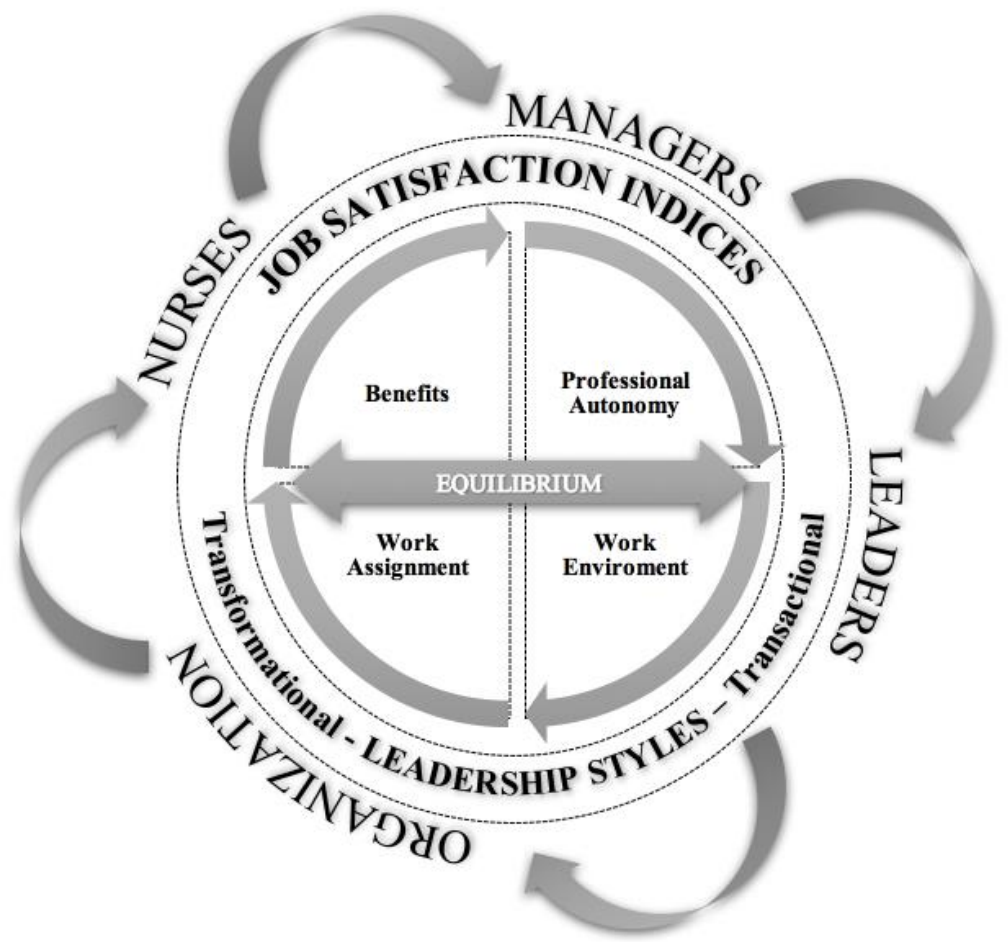

Figure 1. The LS-JS Constellation Model

\section{CONCLUSION}

Despite a growing body of literature extracted about the job satisfaction and leadership styles among nurses from both developed and developing countries, there is a paucity of evidence published among FNs. The findings of this pilot study indicate that FNs are satisfied from the selected four domains of job satisfaction. As FNs embrace their autonomy, positive work environment, flexible work assignment, and generous benefits, the more it contributes to their level of job satisfaction. As nurse managers take a significant part in the lives of nurses, they should learn to respond to the needs of their staff. The way they should manage would depend on a given situation where either transformational or transactional could be more appropriate. Also, the finding of this study argues that FNs opt to choose transformational over the transactional leadership styles. Since the daily operations in any nursing unit vary from a different setting, leadership styles can also be flexible in a manner that it meets the vision towards sustainable organizational functioning and efficient staff performance. Reframing the concepts of leadership styles should be understood by the nurse managers to maintain a state of balance between transformational and transactional attributes. Despite extensive research on the preferences of the transformational over the other, the balance would 
further benefit strengthening an open work environment, systematic management processes, and collegial relationships between and among the members of the hospital community.

\section{REFERENCES}

Aarons, G. A. (2006). Transformational and transactional leadership: Association with attitudes toward evidence-based practice. Psychiatric services (Washington, D.C.), 57(8), 1162-1169. doi:10.1176/appi.ps.57.8.1162

Abdelhafiz, I. M., Alloubani, A. M., \& Almatari, M. (2016). Impact of leadership styles adopted by head nurses on job satisfaction: A comparative study between governmental and private hospitals in Jordan. Journal of Nursing Management, 24(3), 384-392. doi:10.1111/jonm.12333

Abualrub, R. F., \& Alghamdi, M. G. (2012). The impact of leadership styles on nurses' satisfaction and intention to stay among Saudi nurses. Journal of Nursing Management, 20(5), 668-678. doi:10.1111/j.1365-2834.2011.01320.x

Al-Shamari, B., Paulose, J., Ou, C., \& Ngwakongnwi, E. (2015). Multifactor examination of nursing job satisfaction: a cross-sectional survey in a tertiary hospital, Qatar. International Journal of Nursing, 4(1).

Alsaraireh, F., Quinn Griffin, M. T., Ziehm, S. R., \& Fitzpatrick, J. J. (2014). Job satisfaction and turnover intention among Jordanian nurses in psychiatric units. International Journal of Mental Health Nursing, 23(5), 460-467.

Atefi, N., Lim Abdullah, K., Wong, L. P., \& Mazlom, R. (2015). Factors influencing job satisfaction among registered nurses: a questionnaire survey in Mashhad, Iran. Journal of Nursing Management, 23(4), 448-458. doi:10.1111/jonm.12151

Bai, J. (2016). Does job satisfaction mediate the relationship between healthy work environment and care quality? Nursing in Critical Care, 21(1), 18-27.

Bass, B. M. (1985). Leadership and performance beyond expectations. New York: The Free Press.

Burke, R. J. (2004). Encyclopedia of health care management. In M. J. Stahl (Ed.). Thousand oaks, California: SAGE Publications, Inc. Retrieved from http://sk.sagepub.com/reference/healthcaremanagement doi:10.4135/9781412950602

Burns, J. M. (1978). Leadership. New York: Harper \& Row.

Burns, J. M. (2003). Transforming leadership: A new pursuit of happiness (Vol. 213): Grove Press.

De Cremer, D. (2003). Why inconsistent leadership is regarded as procedurally unfair: The importance of social self-esteem concerns. European Journal of Social Psychology, 33(4), 535-550.

Delobelle, P., Rawlinson, J. L., Ntuli, S., Malatsi, I., Decock, R., \& Depoorter, A. M. (2011). Job satisfaction and turnover intent of primary healthcare nurses in rural South Africa: A questionnaire survey. Journal of Advanced Nursing, 67(2), 371383.

Galletta, M., Portoghese, I., Coppola, R. C., Finco, G., \& Campagna, M. (2016). Nurses well-being in intensive care units: Study of factors promoting team commitment. Nursing in Critical Care, 21(3), 146-156. doi:10.1111/nicc.12083

Goh, Y.-S., Lee, A., Chan, S. W.-C., \& Chan, M. F. (2015). Profiling nurses' job satisfaction, acculturation, work environment, stress, cultural values and coping 
abilities: A cluster analysis. International Journal of Nursing Practice, 21(4), 443452.

Goh, Y. S., \& Lopez, V. (2016). Job satisfaction, work environment and intention to leave among migrant nurses working in a publicly funded tertiary hospital. Journal of Nursing Management, 24(7), 893-901. doi:10.1111/jonm.12395

Gurková, E., Čáp, J., Žiaková, K., \& Durišková, M. (2012). Job satisfaction and emotional subjective well-being among Slovak nurses. International nursing review, 59(1), 94-100. doi:10.1111/j.1466-7657.2011.00922.x

Herzberg, F. I. (1966). Work and the nature of man. Cleaveland and New York: World Publishing Company.

Huong Nguyen, T. T., \& Prachusilpa, G. (2016). Factors related to job satisfaction of professional nurses, Hanoi, Vietnam. European Scientific Journal, 12(23).

IBM Corp. (2015). SPSS: IBM SPSS Statistics for Macintosh (Version 23). Armonk, NY: IBM Corporation.

Ibrahim, N. K., Alzahrani, N. A., Batwie, A. A., Abushal, R. A., Almogati, G. G., Sattam, M. A., \& Hussin, B. K. (2016). Quality of life, job satisfaction and their related factors among nurses working in King Abdulaziz University Hospital, Jeddah, Saudi Arabia. Contemporary Nurse, 52(4), 486-498. doi:10.1080/10376178.2016.1224123

Jiang, H., Li, C., Gu, Y., \& Lu, H. (2016). Nurse Satisfaction and Burnout in Shanghai Neurology Wards. Rehabilitation Nursing, 41(2), 120-127. doi:10.1002/rnj.174

Judge, T. A., \& Klinger, R. (2008). Job Satisfaction. In M. Eid \& R. Larsen (Eds.), The Science of Subjective Well-Being (pp. 392-413). New York: Guilford Publications.

Kubichka, M. M. (2016). The influence of perceived same-status nurse-to-nurse coworker exchange relationships, quality of care provided, overall nurse job satisfaction, and organizational commitment on intent to stay and job search behavior of nurses in the acute care nurse work environment. (10123784 Ph.D.), The University of Wisconsin, Milwaukee. Retrieved from https://search.proquest.com/docview ProQuest Dissertations \& Theses Global database.

Kuwano, N., Fukuda, H., \& Murashima, S. (2016). Factors affecting professional autonomy of Japanese nurses caring for culturally and linguistically diverse patients in a hospital setting in Japan. Journal of Transcultural Nursing, 27(6), 567-573. doi:10.1177/1043659615587588

Laschinger, H. K., Zhu, J., \& Read, E. (2016). New nurses' perceptions of professional practice behaviours, quality of care, job satisfaction and career retention. Journal of Nursing Management, 24(5), 656-665. doi:10.1111/jonm.12370

Leineweber, C., Chungkham, H. S., Lindqvist, R., Westerlund, H., Runesdotter, S., Smeds Alenius, L., \& Tishelman, C. (2016). Nurses' practice environment and satisfaction with schedule flexibility is related to intention to leave due to dissatisfaction: A multi-country, multilevel study. International Journal of Nursing Studies, 58, 47-58. doi:10.1016/j.ijnurstu.2016.02.003

Locke, E. A. (1976). The nature and causes of job satisfaction. In M. D. Dunnette (Ed.), Handbook of industrial and organizational psychology (pp. 1297-1350). Illinois, USA: Rand McNally. 
Lorenzo, F. M. E., Galvez-Tan, J., Icamina, K., \& Javier, L. (2007). Nurse migration from a source country perspective: Philippine country case study. Health Services Research, 42(3 Pt 2), 1406-1418. doi:10.1111/j.1475-6773.2007.00716.x

Maslow, A. H. (1943). A theory of human motivation. Psychological Review, 50(4), 370.

Maurits, E. E., de Veer, A. J., Groenewegen, P. P., \& Francke, A. L. (2017). Home-care nursing staff in self-directed teams are more satisfied with their job and feel they have more autonomy over patient care: A nationwide survey. Journal of Advanced Nursing, 73(10), 2430-2440. doi:10.1111/jan.13298

Miller, L. (2017). Balancing leadership styles. Retrieved from http://www.theherald.com.au/

Morsiani, G., Bagnasco, A., \& Sasso, L. (2017). How staff nurses perceive the impact of nurse managers' leadership style in terms of job satisfaction: A mixed method study. Journal of Nursing Management, 25(2), 119-128. doi:10.1111/jonm.12448

Naveed, I., Hussain, A., Sarfraz, M., Afghan, S., \& Waqar, S. H. (2016). Assessment of job satisfaction among nurses working in children hospital, Pakistan Institute of Medical Sciences, Islamabad. Pakistan Journal of Medical Research, 55(4), 116120.

Pastor, D. C. (2015, August 16, 2015 ). Filipino nurses in high demand in US health facilities. Retrieved from http://www.rappler.com/move-ph/balikbayan

Perez, J. L. (2014). Impact of Nurse Managers' Leadership Styles on Staff Nurses' Intent to Turnover. (Master of Science in Nursing), Gardner-Webb University, Boiling Springs. Retrieved from http://digitalcommons.gardner-webb.edu/nursing_etd

Polit, D. F., \& Beck, C. T. (2016). Nursing research: generating and assessing evidence for nursing practice (9th ed.): Lippincott Williams \& Wilkins.

Singh, P., \& Loncar, N. (2010). Pay satisfaction, job satisfaction and turnover intent. Relations Industrielles, 65(3), 470-490. doi:10.7202/044892ar

Spector, P. (1997). Job satisfaction: application, assessment, causes, and consequences. In. Thousand Oaks, California: SAGE Publications, Inc. Retrieved from http://sk.sagepub.com/books/job-satisfaction. doi:10.4135/9781452231549

Stuart, E. H., Jarvis, A., \& Daniel, K. (2008). A ward without walls? District nurses' perceptions of their workload management priorities and job satisfaction. Journal of Clinical Nursing, 17(22), 3012-3020.

Tayao-Juego, A. (2016). PH nurses unite to fight contractualization. Retrieved from http://globalnation.inquirer.net

The Manila Times. (2016). 200,000 registered nurses are jobless. Retrieved from http://www.manilatimes.net

Tuppal, C. P. (2017). A Cloud Drifting from Silent Darkness: Workplace Incivility and Professional Quality of Life among Filipino Educated Nurses. Germany: Scholar's Press.

Ugwa, E. (2014). A cross-sectional study of job satisfaction and leadership styles among the nurses in Aminu Kano teaching hospital. Nigerian Journal of Basic and Clinical Sciences, 11(2), 114-120. doi:10.4103/0331-8540.140363

Van Bogaert, P., Clarke, S., Willems, R., \& Mondelaers, M. (2013). Nurse practice environment, workload, burnout, job outcomes, and quality of care in psychiatric hospitals: A structural equation model approach. Journal of Advanced Nursing, 69(7), 1515-1524. 
Wang, Y., Dong, W., Mauk, K., Li, P., Wan, J., Yang, G., . . Hao, M. (2015). Nurses' practice environment and their job satisfaction: A study on nurses caring for older adults in Shanghai. Plos One, 10(9). doi:10.1371/journal.pone.0138035

Wong, C. A. (2015). Connecting nursing leadership and patient outcomes: State of the science. Journal of Nursing Management, 23(3), 275-278. doi:10.1111/jonm.12307

Wu, L. C., Maa, S. H., Chung, T. C., Huang, K. H., Hsieh, M. C., \& Chen, C. H. (2014). A pilot study of the professional autonomy, job satisfaction, and related factors of nurses at a regional hospital. Journal of Nursing, 61(5), 54-65. doi:10.6224/JN.61.5.54 